\title{
Pharmacology and rationale for imatinib in the treatment of scleroderma
}

\author{
This article was published in the following Dove Press journal: \\ Journal of Experimental Pharmacology \\ 4 April 2013 \\ Number of times this article has been viewed
}

\section{Pia Moinzadeh \\ Nicolas Hunzelmann \\ Thomas Krieg \\ Department of Dermatology and Venerology, University of Cologne, Germany}

Correspondence: Pia Moinzadeh Department of Dermatology and Venerology, University of Cologne, Kerpener Str 62, 50937 Cologne, Germany

Tel +49 22I 4784500

Fax +49 22I 4784538

Email pia.moinzadeh@uk-koeln.de

\begin{abstract}
Systemic sclerosis (scleroderma) is a chronic, multisystem, fibrotic disease. Although the pathogenesis is not completely understood, early vascular damage leads to an inflammatory reaction and a severe fibrotic response. Therapy of systemic sclerosis is still not convincing and is mainly restricted to the management of organ complications. A wide choice of immunosuppressive and antifibrotic drugs has been used to try to modify the course of the disease, but significant breakthroughs are still lacking. Imatinib is a tyrosine kinase inhibitor known to regulate growth, proliferation, and differentiation as well as apoptosis of cells and is already widely used for several malignancies, eg, chronic myeloid leukemia and gastrointestinal stromal tumors. It has been used in preclinical as well as clinical studies to modulate the fibrotic process in patients with systemic sclerosis. This is based on its activity to interfere selectively with both the transforming growth factor- $\beta$ and platelet-derived growth factor signaling pathway. Preclinical studies in mouse models of scleroderma showed significant anti-inflammatory and antifibrotic effects; however, several clinical, proof-of-concept trials have not yet confirmed these initially promising results.
\end{abstract}

Keywords: scleroderma, systemic sclerosis, SSc, tyrosine kinase inhibitor, imatinib

\section{Introduction to scleroderma}

Scleroderma, or systemic sclerosis ( $\mathrm{SSc}$ ), is a multisystem disorder with a very heterogeneous course. It is characterized by the development of fibrosis of the skin and several internal organs. The pathogenesis of scleroderma is still not completely uncovered. It is based on vascular/endothelial cell injury, an altered immune response as well as an extensive fibrotic process, finally leading to induced production and deposition of collagen as well as other extracellular matrix proteins. ${ }^{1}$

The accumulation of extracellular matrix proteins results in distinctive hardening of the skin and is responsible for the severe dysfunction/failure of affected organs (lung, heart, kidneys, gastrointestinal tract, and vascular system). ${ }^{1}$

Due to the heterogeneous character of the disease and according to the different SSc subsets, the incidence, prevalence, mortality rates vary widely. Incidence rates vary from $0.1-4.3$ patients per 100.000 inhabitants. This is also reflected in the prevalence rates, which vary between $1.5-34$ patients per 100.000 inhabitants per year. ${ }^{2-11}$

The American College of Rheumatology published in 1980 preliminary classification criteria for patients suffering from SSc to simplify the classification of those patients with definite SSc disease. ${ }^{12}$ LeRoy et al differentiated between limited versus diffuse cutaneous SSc based on a number of clinical characteristics, including extension of 
skin hardening, specific autoantibodies, and changes of capillaries localized within the nailfold. ${ }^{13}$

Patients suffering from the limited form of SSc represent $43 \%$ (data from the German Network for SSc), the most common subgroup. ${ }^{14-16}$ These patients develop disease manifestations with skin hardening and/or internal organ involvement, usually with a delay of several years after the initial Raynaud's phenomenon. The skin of these patients is mainly affected below the elbow and knee joints and often the face will also be involved. They also show an increased risk of developing gastrointestinal involvement as well as primary pulmonary arterial hypertension (PAH) in later stages of disease. Furthermore, patients with limited SSc more frequently show acral, facial, and/or intestinal telangiectasias. They are frequently characterized by anticentromere autoantibodies. . $^{15,16}$

Patients suffering from the diffuse form of SSc (32\%) are characterized by an early onset of Raynaud's phenomenon and the development of further non-Raynaud's phenomenon symptoms within 1 year. The course of this disease variant is more progressive with more extensive skin involvement of the trunk, face, upper arms, and thighs shortly after Raynaud's phenomenon onset. Patients with diffuse SSc are most frequently anti-Scl 70 (anti-topoisomerase-I) or anti-ribonucleic acid polymerase-III antibody positive, with a higher risk of developing interstitial lung disease, cardiac involvement, and scleroderma renal crisis during the course of disease. ${ }^{15,16}$

Patients with symptoms of SSc simultaneously with those of other connective tissue diseases such as myositis, Sjogren's syndrome, or lupus erythematosus are classified as scleroderma overlap syndrome and are characterized by typical autoantibodies such as Pm-Scl, U1-RNP, and Jo-1..$^{15,17,18}$

Damage of the vascular system and endothelial cells is an early event in SSc. This leads to the release of cytokines/ chemokines, causing tissue inflammation with the response of the immune system and resulting in the production of scleroderma-specific autoantibodies. Cytokines, chemokines, and growth factors play a key role in the transformation of fibroblasts to myofibroblasts and the overproduction of collagen and extracellular matrix proteins. ${ }^{1}$

Fibrosis represents one of the main hallmark features in SSc based on the synthesis of increased quantities of fibronectin, fibrillins, proteoglycan core proteins, and particularly collagen types I and III. Profibrotic cytokines and chemokines, such as transforming growth factor- $\beta$ (TGF- $\beta$ ), connective tissue growth factor (CCN2), platelet-derived growth factor (PDGF), endothelin-1, interleukins, and monocyte chemoattractant proteins (MCP-1 and MCP3 ), participate as major proponents in the initiation of fibrosis. ${ }^{19}$

TGF- $\beta$ is one of the most potent profibrotic growth factors, stimulating fibroblasts to proliferate, migrate, and transdifferentiate into myofibroblasts. Enhanced levels of TGF- $\beta$ have also been observed in serum/plasma, skin tissue, bronchoalveolar lavage, and blister fluid. It is overexpressed in the early fibrotic process, leading to the induction of signaling through both the Smad-dependent $(\operatorname{Smad} 2 / 3)$ and Smad-independent pathway. ${ }^{1,20}$ TGF- $\beta$ is also capable of inducing fibrosis independently of the Smad2/3 complex as well as PDGF receptor (PDGFR) signaling through the c-Abelson (c-Abl) kinase pathway. ${ }^{21}$

PDGF is a dimeric peptide growth factor which can induce migration, differentiation, and transformation of different cells. These broad activities explain why PDGF also plays an important role in other disease processes, such as wound healing, ${ }^{22} \mathrm{PAH},{ }^{23}$ and interstitial lung disease. ${ }^{24} \mathrm{~A}$ recent preclinical study analyzed the impact of PDGFR and its signaling pathways in the pathogenetic process of pulmonary vascular remodeling, which showed that overexpression of PDGFRs and its ligands are increased compared to healthy subjects. In vitro and in vivo investigations have shown that the combination of PDGFR/c-Abl together with Src-inhibition reduced the response of pulmonary arterial smooth muscle cells to growth factor effects and improved vascular remodeling in experimental $\mathrm{PAH}^{25}$

\section{Imatinib: mode of action, pharmacology, pharmacokinetics, and comparison with other therapy options}

Imatinib (Glivec ${ }^{\circledR}$; Novartis Pharma AG, Basel, Switzerland) is a small-molecule tyrosine kinase inhibitor that regulates many physiological cellular processes, including metabolism, growth/ proliferation, differentiation, adhesion, and apoptosis. ${ }^{26-28}$

Imatinib has been approved for the treatment of several malignancies, ie, chronic myeloid leukemia (associated with the Philadelphia chromosome transformation; Bcr-Abl translocation), ${ }^{29}$ myelodysplastic/myeloproliferative diseases associated with PDGFR gene rearrangements, ${ }^{30}$ hypereosinophilic syndrome, ${ }^{31}$ chronic eosinophilic leukaemia, ${ }^{32}$ gastrointestinal stromal tumors, ${ }^{33,34}$ aggressive systemic mastocytosis (with D816V mutation), ${ }^{35}$ and nonresectable dermatofibrosarcoma protuberans. ${ }^{36}$ 
Imatinib is administered orally and absorbed with a mean time to maximum plasma concentration of 2-4 hours, ${ }^{37,38}$ without significant changes when taken in combination with food or under fasting conditions. ${ }^{39}$ The standard dose in adults is $400-800 \mathrm{mg} /$ day, whereas children are treated with a standard daily dosage of $340 \mathrm{mg} / \mathrm{m}^{2}{ }^{20}$ Plasma levels of imatinib usually remain stable after achieving the steady state. ${ }^{37}$ The bioavailability of imatinib exceeds $90 \%$ from either tablets or capsules and its metabolism takes place predominantly in the liver, mediated by isoenzymes of the cytochrome P450 (CYP450) system, including CYP3A4/5 and, to a lesser extent, CYP1A2, CYP2D6, CYP2C9, and CYP2C19. ${ }^{38}$ It is a substrate for the adenosine triphosphate-binding cassette $(\mathrm{ABC})$ transporters $\mathrm{ABCB} 1$ and $\mathrm{ABCG} 2$ and is mainly bound to plasma proteins such as $\alpha-1$ acid glycoprotein, ${ }^{40}$ which influences its pharmacokinetics. ${ }^{41}$ Imatinib and its main and also active metabolite, $\mathrm{N}$-demethylated piperazine derivative, are eliminated through the bile and feces with just a small amount of the given dose of imatinib, secreted via the urine. This explains why a variation in bioavailability is mainly caused by changes in metabolism or distribution of imatinib. ${ }^{42}$ Other drugs are known to induce CYP3A4/5 levels (eg, rifampicin, St John's wort), leading to a reduction in imatinib plasma levels, while drugs which inhibit CYP 3 A $4 / 5$ can cause an increase in imatinib concentrations (eg, ketoconazole, itraconazole, clarithromycin, grapefruit juice). Conversely, imatinib may also act as an inhibitor of CYP3A4, CYP2C9, and CYP2D6 and may therefore alter the plasma levels of other drugs such as cyclosporin A, simvastatin, pimozide, warfarin, metoprolol, and paracetamol. The toxicities of imatinib are mainly dose-related. ${ }^{38,40}$

Imatinib is a 2-phenylaminopyrimidine derivative and works through inhibition of several tyrosine kinases. It binds to the adenosine triphosphate-binding site of the kinase, blocking the phosphorylation of its targets (protein tyrosine phosphorylation) and consequently inhibiting the induction of intracellular signal transduction pathways. It is known to interfere selectively with both TGF- $\beta$ and PDGF signaling pathways by blocking c-Abl and PDGFR, respectively (Figure 1). Apart from that, imatinib also works through Arg (Abl-related genes) kinases and c-Kit (stem cell factor receptor). ${ }^{43-46}$

Imatinib is thought to affect the main pathways in the fibrotic process instead of inhibiting the immune reaction and inflammation in SSc patients. It is hypothesized that imatinib might prevent the progression of skin hardening and organ fibrosis, whilst improving established fibrotic tissue alterations. ${ }^{47}$

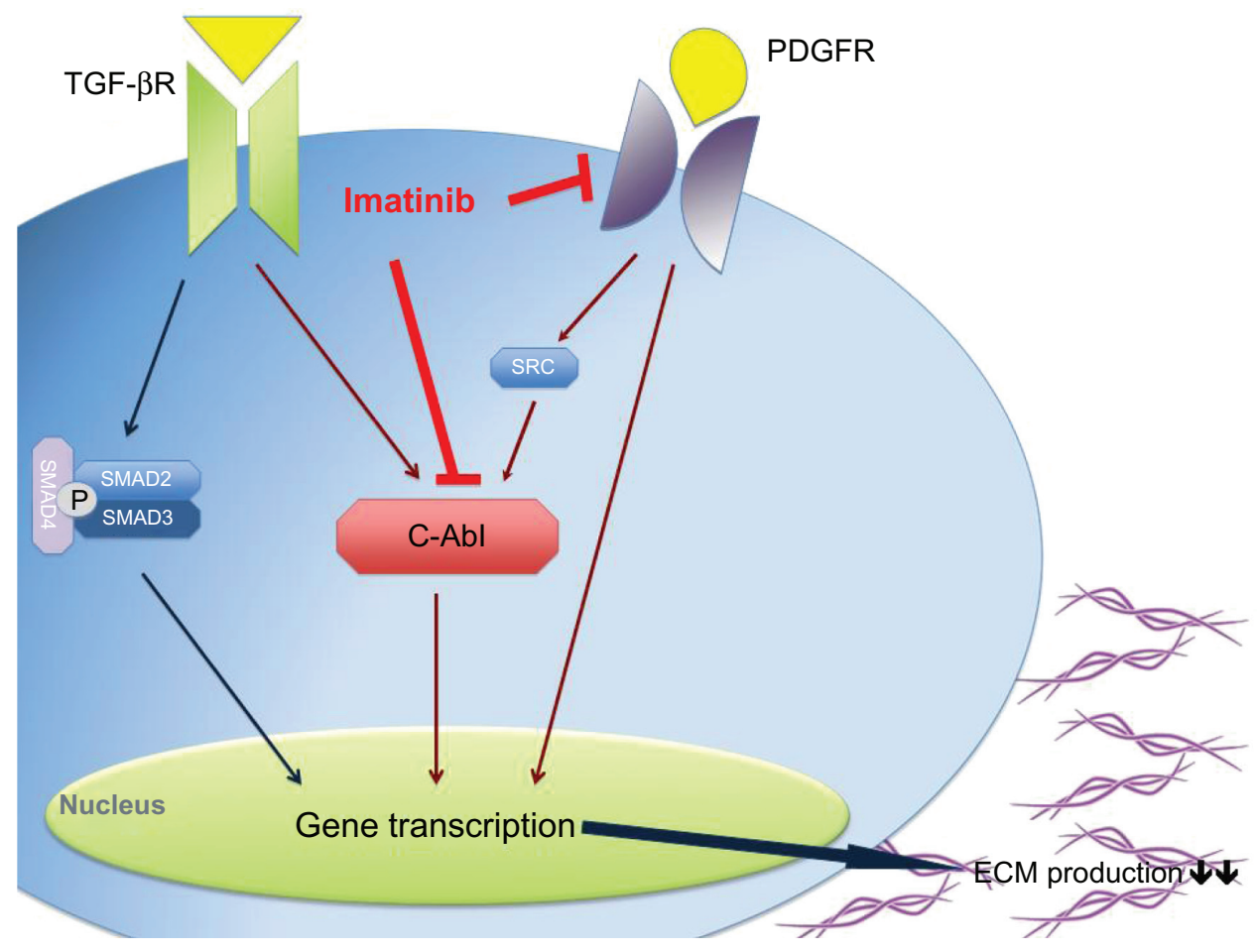

Figure I Imatinib seems to work in systemic sclerosis patients through the inhibition of the TGF- $\beta$ and PDGF signaling pathway via c-Abl and directly by blocking PDGFR, which results in a decrease of gene transcription and consequently in a decrease in collagen production.

Abbreviations: c-Abl, c-Abelson; ECM, extracellular matrix proteins; PDGF, platelet-derived growth factor; PDGFR, platelet-derived growth factor receptor; TGF- $\beta$, transforming growth factor- $\beta$; TGF- $\beta$ R, transforming growth factor- $\beta$ receptor. 
In previous clinical trials, for example in patients with chronic myeloid leukemia, imatinib has been well tolerated with the number of severe adverse side effects (eg, edema, rash, muscle cramps, diarrhea, bone marrow suppression) being less than $1 \%$ of subjects compared to SSc patients who developed overtly greater and more severe side effects in clinical studies. ${ }^{48}$

In some patients, imatinib can cause congestive heart failure (toxic cardiomyopathy/cardiotoxicity) - with an incidence of $1.7 \%$ - and hepatotoxicity. ${ }^{49,50}$

\section{Rationale for imatinib for the treatment of scleroderma}

Scleroderma (SSc) is a heterogeneous, multisystem disease. Its pathogenesis has not been fully elucidated, explaining the lack of optimal treatment options. It is characterized by a severe fibrotic reaction in response to tissue damage caused by cytokines/growth factors such as PDGF and TGF- $\beta$, which have been identified as key mediators and result in the activation of fibroblasts in SSc. PDGF is also a major regulator of the vascular processes/angiogenesis and is known to be involved in SSc-associated PAH. ${ }^{51}$

Imatinib can interact with both important profibrotic pathways contemporarily through PDGFR/c-Abl (important downstream signaling molecule of TGF- $\beta$ and PDGF) and the Smad1/CCN2 pathway. ${ }^{52,53}$

Preclinical studies have shown that the inhibition of c-Abl leads to a decrease in type I collagen and fibronectin-1 synthesis by dermal fibroblasts and myofibroblasts. ${ }^{54}$ They also showed a reduction in messenger ribonucleic acid synthesis of collagen and fibronectin in scleroderma and normal fibroblasts after imatinib treatment. ${ }^{54}$

Hinchcliff et al demonstrated in their study that imatinib changed the gene signature of SSc dermal fibroblasts after treatment compared to healthy subjects. ${ }^{55}$

Soria et al showed that imatinib was able to block the proliferation of normal and scleroderma fibroblasts by inhibiting the phosphorylation of PDGFRs. ${ }^{56}$ In addition, Furspan et al demonstrated a positive correlation of the degree of vasoconstriction of isolated arterioles of SSc patients and healthy controls with the degree of tyrosine phosphorylation in vascular smooth muscle cells. Additionally, imatinib improved and reduced vasoconstriction after cold exposure. ${ }^{57}$

Mice that developed lung fibrosis after bleomycin-exposure were treated with imatinib at doses of $50 \mathrm{mg} / \mathrm{kg} /$ day and $150 \mathrm{mg} / \mathrm{kg} /$ day, with a clear beneficial antifibrotic effect with minimal toxic side effects. ${ }^{21}$
Another study using animal models demonstrated that imatinib could prevent bleomycin-induced fibrosis, but failed to improve bleomycin-induced preexisting dermal fibrosis. ${ }^{54}$ These findings indicate that imatinib is more effective in blocking early ongoing fibrotic processes than dissolving already established, burned-out fibrotic tissue. Imatinib was also effective in preventing bleomycin or radiation-induced interstitial lung disease in mouse models. ${ }^{21,58-60}$

A positive effect of imatinib has also been reported in other sclerotic diseases such as graft-versus-host disease, ${ }^{61-63}$ localized scleroderma (morphea), ${ }^{64}$ and nephrogenic systemic fibrosis. ${ }^{65,66}$

\section{Efficacy, safety, and tolerability studies and patient-focused perspectives: quality of life, satisfaction and acceptability, adherence, and uptake}

On the basis of all preclinical studies, several case reports have suggested a clinical benefit within 3-6 months of treatment with imatinib in patients with SSc. All reported a reduction in skin fibrosis detected by modified Rodnan skin score (MRSS) and an increase in lung function. ${ }^{47,67,68} \mathrm{~A}$ recent case series of six scleroderma patients reported a clear reduction in skin hardening as well as a stabilization in lung function after treatment with a dosage of $200 \mathrm{mg} /$ day for a median period of 23 months. ${ }^{69}$

To confirm these findings, several clinical trials were initiated with controversial results.

Pope et al performed a 6-month, randomized, double-blind, placebo-controlled, proof-of-concept pilot study that included patients with active diffuse SSc. Ten diffuse SSc patients were randomized, and four completed the study with a dosage of $400 \mathrm{mg} /$ day. After randomizing, further enrollment was stopped due to a poor overall tolerance (fatigue, weakness, tiredness, fluid retention, nausea, constipation, diarrhea, and anemia) and two serious adverse events. Side effects occurred in both patients at very early stages during treatment, with relapses of side effects also after readministration of reduced dosages. No significant effect was detectable. ${ }^{70}$

Tamaki et al showed in their pilot study that a dose of $100 \mathrm{mg} /$ day improved symptoms in five patients with $\mathrm{PAH}$, including three SSc patients, over a period of 6 months. No significant effects were detectable on hemodynamics or exercise capacity, but two SSc patients showed a reduction in vascular pulmonary resistance as well as an improvement in the predicted diffusion lung capacity for carbon monoxide. All three patients showed an improvement in skin thickening and mobility. Nailfold 
capillary changes, especially hemorrhages, disappeared after 6 months of treatment. Interestingly, none of the three patients developed side effects; only one patient suffered from transient renal dysfunction. ${ }^{71}$ These data indicate that imatinib has more beneficial effects on skin manifestation than on pulmonary involvement. This could be in agreement with the four-fold increase in the $\alpha-1$ acid glycoprotein level in bronchoalveolar lavage fluids compared to serum levels of SSc patients and healthy controls, which is known to block the inhibitory effects of imatinib. ${ }^{71-73}$

Hatano et al showed that patients with PAH have increased PDGF-BB serum levels, which declined after the treatment with imatinib. Interestingly, patients with increased PDGF-BB levels within the early stage of disease showed an improvement $(>15 \%$ decrease in pulmonary vascular resistance) following imatinib treatment. ${ }^{74}$

Khanna et al conducted a 1-year, Phase I/IIa, open-label pilot study that treated $20 \mathrm{SSc}$ patients with SSc-associated interstitial lung disease with oral imatinib (up to $600 \mathrm{mg}$ /day). Five patients developed adverse events, including generalized edema, shortness of breath, diastolic dysfunction, generalized rash, diarrhea, hepatotoxicity, elevated creatine kinase levels, and anemia. Three of these five patients suffered from marked anemia, fatigue, and muscle weakness combined with gastric antral vascular ectasia. Dyspnea and generalized edema was observed in the other two patients. There was a significant improvement in MRSS (3.9 units; $P<0.001$ ) as well as a trend towards improvement in parameters in lung function tests (1.74\% increase in forced vital capacity, $4.17 \%$ increase in total lung capacity, and a $1.46 \%$ increase in the diffusing capacity of the lung for carbon monoxide). ${ }^{75}$

Spiera et al administered imatinib in their 1-year, Phase IIa, single-arm, open-label study in a daily dosage of $400 \mathrm{mg}$ for 12 months in 30 patients with early diffuse SSc. Of these, 24 patients completed the 12-month treatment period. There were 171 adverse events that appeared to be related to the drug intake. Serious adverse events were detectable in 24 patients; however, they were not all related to the study medication. An improvement in skin thickening was detectable in early and late stage patients (decline in MRSS by 6.6 points or $22.4 \%$; $P<0.001$ ), as well as a significant improvement in forced vital capacity (improvement by $6.4 \% ; P<0.008$ ), while the diffusion capacity just stabilized and skin morphology (collagen deposition) changed. Health-related quality of life assessment improved or remained stable during the study. ${ }^{76}$

A multicenter, open-label, proof-of-concept, Phase IIa study enrolled 27 patients who were started on $200 \mathrm{mg} /$ day imatinib, which was then titrated up to $600 \mathrm{mg} /$ day.
Sixteen of the 27 patients completed 24 weeks of treatment, but unfortunately no significant changes in skin score and/ or lung function was observable. ${ }^{77}$

Chung et al investigated whether treatment with imatinib would have an impact on gene expression signature in skin biopsies. They included seven patients with diffuse SSc and two patients with limited SSc and administered dosages between 100-400 mg/day for 24 weeks. Improvement in skin thickening (32\% improvement in MRSS; $P=0.05)$ was detectable in seven patients who completed 24 weeks of treatment with a mean dose of $300 \mathrm{mg} /$ day. Changes of gene expression pre- and posttreatment with imatinib were investigated and a change in gene signature of skin biopsies in three patients who responded to the treatment (upregulation of genes involved in collagen metabolism and downregulation of genes involved in mitosis and cell cycle) was detected. .77, $^{78}$

Sabnani et al showed, that a combination therapy of imatinib (200 mg/day) together with cyclophosphamide (500 mg every 3 weeks) was well-tolerated in five patients with scleroderma-associated interstitial lung disease. ${ }^{79}$

An improvement in $\mathrm{PAH}$ and right ventricular function in a patient with SSc-associated cardiac involvement after imatinib treatment (200-400 mg/day) was reported by ten Freyhaus et al, who suggested that the benefit was induced by an antiproliferative rather than by a vasodilatative effect. ${ }^{23}$

Prey et al recently reported their data of a Phase II, multicenter, randomized, double-blinded, controlled study on patients with morphea $(n=3)$ and $\operatorname{SSc}(n=25)$. Each patient received after randomization either $400 \mathrm{mg}$ /day imatinib or placebo for 6 months, with a follow-up after discontinuation of a further 6 months. The primary outcome was the efficacy based on the change in MRSS; unfortunately no changes in MRSS were observable. Adverse events were more frequent in the group treated with imatinib. ${ }^{80}$

\section{Conclusion and place in therapy}

SSc and its treatment is still a major burden for the affected patient and a challenge for clinicians. To date, SSc is not curable; however, immunosuppressive drugs are frequently used as modifying treatments. Basic research, the search for new therapeutic targets, and new controlled clinical studies/trials are urgently required to improve the course of disease, mortality, and prognosis as well as the quality of life of SSc patients.

On the basis of the data available, it is still very difficult to reach a final conclusion on whether imatinib or its related variants are effective drugs for SSc. This is due to (1) the 
heterogeneity of this disease, which exacerbates the grading of improvement of symptoms; (2) the severity of organ involvements and progression of disease, with an increased risk of developing side effects such as edema, cardiotoxicity, and alveolitis; and (3) the self-limitation of skin-hardening, usually after a period of 3-4 years.

Interestingly, in some reports not only fibrosis improved under treatment, but also vascular alterations. This could be explained by the finding that target molecules of imatinib are also expressed in vascular structures. ${ }^{81}$

Studies using imatinib in the treatment of chronic myeloid leukemia always reported low frequencies of drug-induced adverse events. Much higher doses (up to $800 \mathrm{mg} /$ day) have been used compared to initial studies involving scleroderma patients, which more frequently showed dose-dependent adverse events. This has been the reason for some study interruption and loss to follow-up of patients. SSc patients treated with lower doses of imatinib (200 mg/day) showed a better tolerability. ${ }^{69,71}$ One might hypothesize that this could be explained by the fact that SSc patients suffer from a multisystem disease, including impairment of renal function and/or cardiopulmonary function. Ohnishi et al reported that imatinib-induced interstitial lung disease, occurred more frequently in patients with preexisting lung impairment, which was reversible after stopping treatment. ${ }^{82}$

Due to the variation of efficacy in all mentioned case reports and studies, it would be important to identify patients who would benefit the most. This could be achieved by the development of biomarkers to identify patients, which are associated with a progressive versus mild course of disease, which are associated with rather fibrotic or vascular features and which correlate with the response to therapies.

Tamaki et al suggested that plasma levels of PDGF-BB could serve as a marker for responsiveness to imatinib due to the finding that PDGF plays a major role in skin and vascular involvement in SSc patients and that it decreased after the administration of imatinib. ${ }^{71}$

To date, placebo-controlled studies are still lacking and the published observational studies show conflicting results, balanced with negative and positive effects/findings. Therefore, it is impossible to distinguish between the definite effects of the drug and the normal course of disease. Also, the fact that patients have been treated with other immunosuppressive drugs falsifies the findings and should be considered in future welldesigned, placebo-controlled trials.

There are still many open questions about the efficacy and tolerability of imatinib as an antifibrotic drug in SSc patients. Until now, all studies had limitations, which makes any judgment about positive and negative results very difficult. Further studies should also focus much more on the molecular effects of these antifibrotic drugs. Beyer et al nicely explained in their paper that patients with fibrotic diseases and especially with SSc would need a detailed molecular characterization with the focus on biomarkers which indicate specific profibrotic signaling pathways. ${ }^{83}$

In vitro studies don't completely reflect real life, especially the interplay between different cells and the impact of these cells among one another and under different conditions. Therefore, it would be important to uncover in vivo whether imatinib directly affects human fibroblasts through inhibition within the TGF- $\beta$ and PDGF signaling pathway or whether it also acts indirectly through alteration of other cell types. Furthermore, it should be investigated whether the combination of different tyrosine kinase inhibitors with their corresponding targeted tyrosine kinases would amplify the therapeutic effect. Further studies should also address whether combination with immunosuppressive drugs or other antifibrotic drugs would improve the effect of imatinib.

\section{Disclosure}

The authors report no conflicts of interest in this work.

\section{References}

1. Gabrielli A, Avvedimento EV, Krieg T. Scleroderma. $N$ Engl J Med. 2009;360(19):1989-2003.

2. Alamanos Y, Tsifetaki N, Voulgari PV, et al. Epidemiology of systemic sclerosis in northwest Greece 1981 to 2002. Semin Arthritis Rheum. 2005;34(5):714-720.

3. Allcock RJ, Forrest I, Corris PA, Crook PR, Griffiths ID. A study of the prevalence of systemic sclerosis in northeast England. Rheumatology (Oxford). 2004;43(5):596-602.

4. Arias-Nunez MC, Llorca J, Vazquez-Rodriguez TR, et al. Systemic sclerosis in northwestern Spain: a 19-year epidemiologic study. Medicine (Baltimore). 2008;87(5):272-280.

5. Lo Monaco A, Bruschi M, La Corte R, Volpinari S, Trotta F. Epidemiology of systemic sclerosis in a district of northern Italy. Clin Exp Rheumatol. 2011;29(2 Suppl 65):S10-S14.

6. Mayes MD. Scleroderma epidemiology. Rheum Dis Clin North Am. 2003;29(2):239-254.

7. Medsger TA Jr. Epidemiology of systemic sclerosis. Clin Dermatol. 1994;12(2):207-216.

8. Silman A, Jannini S, Symmons D, Bacon P. An epidemiological study of scleroderma in the West Midlands. Br J Rheumatol. 1988;27(4): 286-290.

9. Silman AJ. Epidemiology of scleroderma. Ann Rheum Dis. 1991;50(Suppl 4):846-853.

10. Steen VD, MedsgerTA Jr. Epidemiology and natural history of systemic sclerosis. Rheum Dis Clin North Am. 1990;16(1):1-10.

11. Tamaki T, Mori S, Takehara K. Epidemiological study of patients with systemic sclerosis in Tokyo. Arch Dermatol Res. 1991;283(6): 366-371.

12. Subcommittee for scleroderma criteria of the American Rheumatism Association Diagnostic and Therapeutic Criteria Committee. Preliminary criteria for the classification of systemic sclerosis (scleroderma). Arthritis Rheum. 1980;23(5):581-590. 
13. LeRoy EC, Black C, Fleischmajer R, et al. Scleroderma (systemic sclerosis): classification, subsets and pathogenesis. J Rheumatol. 1988;15(2):202-205.

14. Hunzelmann N, Krieg T. [The German Network for Systemic Sclerosis (DNSS): current data on diagnostics and therapy]. Hautarzt. 2012;63(Suppl 1):71-75. German.

15. Hunzelmann N, Genth E, Krieg T, et al. The registry of the German Network for Systemic Scleroderma: frequency of disease subsets and patterns of organ involvement. Rheumatology (Oxford). 2008;47(8): 1185-1192.

16. Moinzadeh P, Fehr A, Damm B, Krieg T, Hunzelmann N. [The German Network for Systemic Scleroderma]. Hautarzt. 2007;58(10):858-863. German.

17. Bennett RM. Scleroderma overlap syndromes. Rheum Dis Clin North Am. 1990;16(1):185-198.

18. Pakozdi A, Nihtyanova S, Moinzadeh P, Ong VH, Black CM, Denton CP. Clinical and serological hallmarks of systemic sclerosis overlap syndromes. J Rheumatol. 2011;38(11):2406-2409.

19. Moinzadeh P, Denton CP, Abraham D, et al. Biomarkers for skin involvement and fibrotic activity in scleroderma. J Eur Acad Dermatol Venereol. 2012;26(3):267-276.

20. Reiner JE, Datta PK. TGF-beta-dependent and -independent roles of STRAP in cancer. Front Biosci. 2011;16:105-115.

21. Daniels CE, Wilkes MC, Edens M, et al. Imatinib mesylate inhibits the profibrogenic activity of TGF-beta and prevents bleomycin-mediated lung fibrosis. J Clin Invest. 2004;114(9):1308-1316.

22. Cromack DT, Pierce GF, Mustoe TA. TGF-beta and PDGF mediated tissue repair: identifying mechanisms of action using impaired and normal models of wound healing. Prog Clin Biol Res. 1991;365: 359-373.

23. ten Freyhaus H, Dumitrescu D, Bovenschulte H, Erdmann E, Rosenkranz S. Significant improvement of right ventricular function by imatinib mesylate in scleroderma-associated pulmonary arterial hypertension. Clin Res Cardiol. 2009;98(4):265-267.

24. Saggar R, Lynch JP, Belperio JA, et al. Pulmonary arterial hypertension and lung transplantation. Semin Respir Crit Care Med. 2010;31(2): 147-160.

25. Pullamsetti SS, Berghausen EM, Dabral S, et al. Role of Src tyrosine kinases in experimental pulmonary hypertension. Arterioscler Thromb Vasc Biol. 2012;32(6):1354-1365.

26. Buchdunger E, Zimmermann J, Mett H, et al. Inhibition of the Abl protein-tyrosine kinase in vitro and in vivo by a 2-phenylaminopyrimidine derivative. Cancer Res. 1996;56(1):100-104.

27. Druker BJ, Tamura S, Buchdunger E, et al. Effects of a selective inhibitor of the Abl tyrosine kinase on the growth of Bcr-Abl positive cells. Nat Med. 1996;2(5):561-566.

28. Robinson DR, Wu YM, Lin SF. The protein tyrosine kinase family of the human genome. Oncogene. 2000;19(49):5548-5557.

29. Druker BJ, Talpaz M, Resta DJ, et al. Efficacy and safety of a specific inhibitor of the BCR-ABL tyrosine kinase in chronic myeloid leukemia. N Engl J Med. 2001;344(14):1031-1037.

30. Mesa RA, Steensma DP, Hoyer J, Ketterling RP. Concomitant myelodysplastic syndrome and chronic myeloid leukaemia: treatment outcomes with imatinib mesylate. Br J Haematol. 2003;123(2): 366-367.

31. Antoniu SA. Imatinib mesylate for the treatment of hypereosinophilic syndromes. Curr Opin Investig Drugs. 2006;7(11):980-984.

32. Coutre S, Gotlib J. Targeted treatment of hypereosinophilic syndromes and chronic eosinophilic leukemias with imatinib mesylate. Semin Cancer Biol. 2004;14(4):307-315.

33. Blanke CD, Eisenberg BL, Heinrich MC. Gastrointestinal stromal tumors. Curr Treat Options Oncol. 2001;2(6):485-491.

34. van Oosterom AT, Judson I, Verweij J, et al. Safety and efficacy of imatinib (STI571) in metastatic gastrointestinal stromal tumours: a phase I study. Lancet. 2001;358(9291):1421-1423.

35. Dalal BI, Horsman DE, Bruyere H, Forrest DL. Imatinib mesylate responsiveness in aggressive systemic mastocytosis: novel association with a platelet derived growth factor receptor beta mutation. Am J Hematol. 2007;82(1):77-79.
36. Johnson-Jahangir H, Sherman W, Ratner D. Using imatinib as neoadjuvant therapy in dermatofibrosarcoma protuberans: potential pluses and minuses. J Natl Compr Canc Netw. 2010;8(8):881-885.

37. Druker BJ. Imatinib mesylate in the treatment of chronic myeloid leukaemia. Expert Opin Pharmacother. 2003;4(6):963-971.

38. van Erp NP, Gelderblom H, Guchelaar HJ. Clinical pharmacokinetics of tyrosine kinase inhibitors. Cancer Treat Rev. 2009;35(8):692-706.

39. Sparano BA, Egorin MJ, Parise RA, et al. Effect of antacid on imatinib absorption. Cancer Chemother Pharmacol. 2009;63(3):525-528.

40. Petain A, Kattygnarath D, Azard J, et al. Population pharmacokinetics and pharmacogenetics of imatinib in children and adults. Clin Cancer Res. 2008;14(21):7102-7109.

41. Delbaldo C, Chatelut E, Re M, et al. Pharmacokinetic-pharmacodynamic relationships of imatinib and its main metabolite in patients with advanced gastrointestinal stromal tumors. Clin Cancer Res. 2006;12(20 Pt 1):6073-6078.

42. Boddy AV, Sludden J, Griffin MJ, et al. Pharmacokinetic investigation of imatinib using accelerator mass spectrometry in patients with chronic myeloid leukemia. Clin Cancer Res. 2007;13(14):4164-4169.

43. Okuda K, Weisberg E, Gilliland DG, Griffin JD. ARG tyrosine kinase activity is inhibited by STI571. Blood. 2001;97(8):2440-2448.

44. Buchdunger E, Cioffi CL, Law N, et al. Abl protein-tyrosine kinase inhibitor STI571 inhibits in vitro signal transduction mediated by c-kit and platelet-derived growth factor receptors. J Pharmacol Exp Ther. 2000;295(1):139-145.

45. Heinrich MC, Griffith DJ, Druker BJ, Wait CL, Ott KA, Zigler AJ. Inhibition of c-kit receptor tyrosine kinase activity by STI571, a selective tyrosine kinase inhibitor. Blood. 2000;96(3):925-932.

46. An X, Tiwari AK, Sun Y, Ding PR, Ashby CR Jr, Chen ZS. BCR-ABL tyrosine kinase inhibitors in the treatment of Philadelphia chromosome positive chronic myeloid leukemia: a review. Leuk Res. 2010;34(10): 1255-1268.

47. Distler JH, Distler O. Intracellular tyrosine kinases as novel targets for anti-fibrotic therapy in systemic sclerosis. Rheumatology (Oxford). 2008;47(Suppl 5):v10-v11.

48. Druker BJ, Guilhot F, O’Brien SG, et al. Five-year follow-up of patients receiving imatinib for chronic myeloid leukemia. $N$ Engl $\mathrm{J} \mathrm{Med}$. 2006;355(23):2408-2417.

49. Kerkela R, Grazette L, Yacobi R, et al. Cardiotoxicity of the cancer therapeutic agent imatinib mesylate. Nat Med. 2006;12(8):908-916.

50. Atallah E, Durand JB, Kantarjian H, Cortes J. Congestive heart failure is a rare event in patients receiving imatinib therapy. Blood. 2007;110(4): 1233-1237.

51. Barst RJ. PDGF signaling in pulmonary arterial hypertension. J Clin Invest. 2005;115(10):2691-2694.

52. Bhattacharyya S, Ishida $\mathrm{W}, \mathrm{Wu} \mathrm{M}$, et al. A non-Smad mechanism of fibroblast activation by transforming growth factor-beta via c-Abl and Egr-1: selective modulation by imatinib mesylate. Oncogene. 2009;28(10):1285-1297.

53. Pannu J, Asano Y, Nakerakanti S, et al. Smadl pathway is activated in systemic sclerosis fibroblasts and is targeted by imatinib mesylate. Arthritis Rheum. 2008;58(8):2528-2537.

54. Distler JH, Jungel A, Huber LC, et al. Imatinib mesylate reduces production of extracellular matrix and prevents development of experimental dermal fibrosis. Arthritis Rheum. 2007;56(1):311-322.

55. Hinchcliff M, Huang CC, Ishida W, et al. Imatinib mesylate causes genome-wide transcriptional changes in systemic sclerosis fibroblasts in vitro. Clin Exp Rheumatol. 2012;30(2 Suppl 71):S86-S96.

56. Soria A, Cario-Andre M, Lepreux S, et al. The effect of imatinib (Glivec) on scleroderma and normal dermal fibroblasts: a preclinical study. Dermatology. 2008;216(2):109-117.

57. Furspan PB, Chatterjee S, Freedman RR. Increased tyrosine phosphorylation mediates the cooling-induced contraction and increased vascular reactivity of Raynaud's disease. Arthritis Rheum. 2004;50(5):1578-1585.

58. Akhmetshina A, Venalis $\mathrm{P}$, Dees $\mathrm{C}$, et al. Treatment with imatinib prevents fibrosis in different preclinical models of systemic sclerosis and induces regression of established fibrosis. Arthritis Rheum. 2009;60(1): 219-224. 
59. Aono $\mathrm{Y}$, Nishioka $\mathrm{Y}$, Inayama $\mathrm{M}$, et al. Imatinib as a novel antifibrotic agent in bleomycin-induced pulmonary fibrosis in mice. Am J Respir Crit Care Med. 2005;171(11):1279-1285.

60. Li M, Abdollahi A, Grone HJ, Lipson KE, Belka C, Huber PE. Late treatment with imatinib mesylate ameliorates radiation-induced lung fibrosis in a mouse model. Radiat Oncol. 2009;4:66.

61. Papadakis V, Karakasis D, Sfikakis PP, et al. Is imatinib mesylate a promising drug in scleroderma due to extensive chronic graft-versus-host disease? Leuk Lymphoma. 2009;50(3):471-474.

62. Magro L, Catteau B, Coiteux V, Bruno B, Jouet JP, Yakoub-Agha I. Efficacy of imatinib mesylate in the treatment of refractory sclerodermatous chronic GVHD. Bone Marrow Transplant. 2008;42(11):757-760.

63. Olivieri J, Coluzzi S, Attolico I, Olivieri A. Tirosin kinase inhibitors in chronic graft versus host disease: from bench to bedside. Scientific World Journal. 2011;11:1908-1931.

64. Bibi Y, Gottlieb AB. A potential role for imatinib and other small molecule tyrosine kinase inhibitors in the treatment of systemic and localized sclerosis. J Am Acad Dermatol. 2008;59(4):654-658.

65. Elmholdt TR, Buus NH, Ramsing M, Olesen AB. Antifibrotic effect after low-dose imatinib mesylate treatment in patients with nephrogenic systemic fibrosis: an open-label non-randomized, uncontrolled clinical trial. J Eur Acad Dermatol Venereol. December 20, 2011. [Epub ahead of print.]

66. Kay J, High WA. Imatinib mesylate treatment of nephrogenic systemic fibrosis. Arthritis Rheum. 2008;58(8):2543-2548.

67. Sfikakis PP, Gorgoulis VG, Katsiari CG, Evangelou K, Kostopoulos C, Black CM. Imatinib for the treatment of refractory, diffuse systemic sclerosis. Rheumatology (Oxford). 2008;47(5):735-737.

68. van Daele PL, Dik WA, Thio HB, et al. Is imatinib mesylate a promising drug in systemic sclerosis? Arthritis Rheum. 2008;58(8):2549-2552.

69. Guo L, Chen XX, Gu YY, Zou HJ, Ye S. Low-dose imatinib in the treatment of severe systemic sclerosis: a case series of six Chinese patients and literature review. Clin Rheumatol. 2012;31(9):1395-1400.

70. Pope J, McBain D, Petrlich L, et al. Imatinib in active diffuse cutaneous systemic sclerosis: results of a six-month, randomized, double-blind, placebo-controlled, proof-of-concept pilot study at a single center. Arthritis Rheum. 2011;63(11):3547-3551.

71. Tamaki Z, Asano Y, Hatano M, et al. Efficacy of low-dose imatinib mesylate for cutaneous involvement in systemic sclerosis: a preliminary report of three cases. Mod Rheumatol. 2012;22(1):94-99.

72. Fietta A, Bardoni A, Salvini R, et al. Analysis of bronchoalveolar lavage fluid proteome from systemic sclerosis patients with or without functional, clinical and radiological signs of lung fibrosis. Arthritis Res Ther. 2006;8(6):R160.
73. Azuma M, Nishioka Y, Aono Y, et al. Role of alpha1-acid glycoprotein in therapeutic antifibrotic effects of imatinib with macrolides in mice. Am J Respir Crit Care Med. 2007;176(12):1243-1250.

74. Hatano M, Yao A, Shiga T, Kinugawa K, Hirata Y, Nagai R. Imatinib mesylate has the potential to exert its efficacy by down-regulating the plasma concentration of platelet-derived growth factor in patients with pulmonary arterial hypertension. Int Heart J. 2010;51(4):272-276.

75. Khanna D, Saggar R, Mayes MD, et al. A one-year, phase I/IIa, openlabel pilot trial of imatinib mesylate in the treatment of systemic sclerosis-associated active interstitial lung disease. Arthritis Rheum. 2011;63(11):3540-3546.

76. Spiera RF, Gordon JK, Mersten JN, et al. Imatinib mesylate (Gleevec) in the treatment of diffuse cutaneous systemic sclerosis: results of a 1-year, phase IIa, single-arm, open-label clinical trial. Ann Rheum Dis. 2011;70(6):1003-1009.

77. Bournia VK, Evangelou K, Sfikakis PP. Therapeutic inhibition of tyrosine kinases in systemic sclerosis: a review of published experience on the first 108 patients treated with imatinib. Semin Arthritis Rheum. July 10, 2012. [Epub ahead of print.]

78. Chung L, Ruiz P, Wood T, et al. Evaluation of an imatinib response gene signature in patients with systemic sclerosis. Arthritis Rheum 2010;62:S239.

79. Sabnani I, Zucker MJ, Rosenstein ED, et al. A novel therapeutic approach to the treatment of scleroderma-associated pulmonary complications: safety and efficacy of combination therapy with imatinib and cyclophosphamide. Rheumatology (Oxford). 2009;48(1):49-52.

80. Prey S, Ezzedine K, Doussau A, et al. Imatinib mesylate in scleroderma-associated diffuse skin fibrosis: a phase II multicentre randomized double-blinded controlled trial. Br J Dermatol. 2012;167(5): $1138-1144$

81. Beyer C, Distler JH, Distler O. Are tyrosine kinase inhibitors promising for the treatment of systemic sclerosis and other fibrotic diseases? Swiss Med Wkly. 2010;140:w13050.

82. Ohnishi K, Sakai F, Kudoh S, Ohno R. Twenty-seven cases of drug-induced interstitial lung disease associated with imatinib mesylate. Leukemia. 2006;20(6):1162-1164.

83. Beyer C, Distler JH. Tyrosine kinase signaling in fibrotic disorders: translation of basic research to human disease. Biochim Biophys Acta. June 19, 2012. [Epub ahead of print.]
Journal of Experimental Pharmacology

\section{Publish your work in this journal}

The Journal of Experimental Pharmacology is an international, peerreviewed, open access journal publishing original research, reports, reviews and commentaries on all areas of laboratory and experimental pharmacology. The manuscript management system is completely online and includes a very quick and fair peer-review system.

\section{Dovepress}

Visit http://www.dovepress.com/testimonials.php to read real quotes from published authors. 